\title{
Long-distance transmission over standard fiber by use of mid-way phase conjugation
}

\author{
Zhang, Xiupu; Ebskamp, Frank; Jørgensen, Bo Foged
}

Published in:

I E E E Photonics Technology Letters

Link to article, DOI:

10.1109/68.393217

Publication date:

1995

Document Version

Publisher's PDF, also known as Version of record

Link back to DTU Orbit

Citation (APA):

Zhang, X., Ebskamp, F., \& Jørgensen, B. F. (1995). Long-distance transmission over standard fiber by use of mid-way phase conjugation. I E E E Photonics Technology Letters, 7(7), 819-821.

https://doi.org/10.1109/68.393217

\section{General rights}

Copyright and moral rights for the publications made accessible in the public portal are retained by the authors and/or other copyright owners and it is a condition of accessing publications that users recognise and abide by the legal requirements associated with these rights.

- Users may download and print one copy of any publication from the public portal for the purpose of private study or research.

- You may not further distribute the material or use it for any profit-making activity or commercial gain

- You may freely distribute the URL identifying the publication in the public portal

If you believe that this document breaches copyright please contact us providing details, and we will remove access to the work immediately and investigate your claim 


\title{
Long-Distance Transmission Over Standard Fiber by Use of Mid-Way Phase Conjugation
}

\author{
Xiupu Zhang, Frank Ebskamp, Member, IEEE, and Bo F. Jørgensen
}

\begin{abstract}
In this letter, we predict transmission over more than $6000 \mathrm{~km}$ using standard fiber with the application of mid-way phase-conjugation in a $1.55-\mu \mathrm{m}, 10-\mathrm{Gb} / \mathrm{s} \mathrm{IM} / \mathrm{DD}$ system with inline amplifiers for the power penalty at BER $=10^{-9}$, which is less than $6 \mathrm{~dB}$; the system must operate with an average power into the fiber within the range of -5 to $5 \mathrm{dBm}$.
\end{abstract}

\section{INTRODUCTION}

$\mathbf{T}$ HE majority of the world's deployed fiber is standard single-mode fiber. This fiber type has a somewhat lower attenuation than dispersion-shifted fiber and also a lower price. But unfortunately, the first-order chromatic dispersion effect limits the transmission length of an ideal $10-\mathrm{Gb} / \mathrm{s}$ IM/DD system to about $65 \mathrm{~km}$ for an eye closure of $1 \mathrm{~dB}$ [1]. Extending the transmission length beyond this limit is a crucial aspect for a $10-\mathrm{Gb} / \mathrm{s}$ transmission system. Yariv et $a l$., proposed the application of mid-way phase-conjugation to eliminate the effect of the first-order dispersion for longdistance transmissions [2]. Up to now, a number of experimental demonstrations of long-distance transmissions over several hundred $\mathrm{km}$ of standard fiber have been made by use of this technique [3]-[5]. In this letter we present, for the first time, computer simulations to demonstrate the feasibility of longdistance standard fiber transmissions by use of this technique in a $1.55-\mu \mathrm{m}, 10-\mathrm{Gb} / \mathrm{s} \mathrm{IM} / \mathrm{DD}$ system with in-line amplifiers. From these simulations transmission over standard fiber of more than $6000 \mathrm{~km}$ is predicted.

\section{Simulation MODEL}

The propagation of signals in the nonlinear and dispersive fiber is governed by the nonlinear Schroedinger equation [6]. An intensity-modulated signal, consisting of super-Gaussian shaped pulses (with an exponential power index of 1.436), is launched into the fiber. In this analysis, we use a $2^{7}$ pseudorandom bit sequence. Each in-line amplifier just compensates for the fiber linear loss of each spacing. Furthermore, the average power of each in-line amplifier launched into the fiber is assumed to be equal to the average power of the transmitter into the fiber. The receiver is configured as an optical preamplifier with a gain of $30 \mathrm{~dB}$ and noise figure of $4 \mathrm{~dB}$, a Lorentzian shaped optical filter with a 3-dB bandwidth of $1 \mathrm{~nm}$, an ideal photodiode, and a baseband electrical fourthorder Bessel filter with a 3-dB bandwidth of $6.5 \mathrm{GHz}$.

Manuscript received December 13, 1994; revised March 1, 1995.

The authors are with the Center for Broadband Telecommunications, Electromagnetics Institute, Technical University of Denmark, DK-2800 Lyngby, Denmark.

IEEE Log Number 9411807.
TABLE I

SYSTEM PARAMETERS

\begin{tabular}{|l|l|l|l|l|l|}
\hline Parameter & & & & & \\
\hline Bit rate & 10 & Gbit/s & First-order dispersion & 17 & $\mathrm{ps} / \mathrm{nm} / \mathrm{km}$ \\
\hline Amplifier spacing & 50 & $\mathrm{~km}$ & Second-order dispersion & 0.07 & $\mathrm{ps} / \mathrm{nm}^{2} / \mathrm{km}$ \\
\hline Fiber attenuation & 0.22 & $\mathrm{~dB} / \mathrm{km}$ & Pre-amplifier gain & 30 & $\mathrm{~dB}$ \\
\hline Amplifier gain & 11 & $\mathrm{~dB}$ & Pre-amp noise figure & 4 & $\mathrm{~dB}$ \\
\hline Amplifier noise figure & 5 & $\mathrm{~dB}$ & Opt. filter bandwidth & 1 & $\mathrm{~nm}$ \\
\hline Extinction ratio & 15 & $\mathrm{~dB}$ & Elec. filter bandwidth & 6.5 & $\mathrm{GHIz}$ \\
\hline Non-tinear coefficient & 1.35 & $\mathrm{~km}^{-1} \mathrm{~W} \cdot 1$ & $\mathrm{~m}$ of super-Gauss pulse & 1.436 & \\
\hline
\end{tabular}

In our simulations the assumptions are made that 1) an ideal phase-conjugation is used, which means that the midway phase-conjugator does not distort the signal and no additional ASE noise is added to the system at this point, 2) the chromatic dispersions are identical in all fiber sections before and after the mid-way phase-conjugator, 3) the interaction between signals and ASE noise due to four-wave mixing is neglected because the operating wavelength is far from zerodispersion wavelength and hence the phase-matching condition is not satisfied, and 4) modulation instability incurred by accumulated ASE noise is ignored since this effect is small compared to the signal power.

It is convenient to evaluate the system performance by means of eye closure, but the eye closure only describes the evolution of the signals along the fiber, and does not include amplified spontaneous emission (ASE) noise that is produced by in-line amplifiers. Therefore, even when a good eye is achieved, the system might have a high bit error rate (BER). In this letter both eye closure and power penalty referred to the back-to-back sensitivity at $\mathrm{BER}=10^{-9}$ are simulated simultaneously. The BER is calculated for optimized sampling time and decision threshold as the average error probability of each individual symbol in the sequence. The symbol error probability is determined by the signal to noise ratio using bandpass signal theory and Gaussian noise approximations [7]. The sensitivity of the back-to-back system is $-35 \mathrm{dBm}$ at BER $=10^{-9}$. The system parameters are listed in Table I.

\section{RESULTS}

Fig. 1(a) shows the eye closure and Fig. 1(b) shows power penalty at $\mathrm{BER}=10^{-9}$, respectively, versus transmission length with average power of each in-line optical amplifier into the fiber as a parameter in the $10 \mathrm{~Gb} / \mathrm{s}$ IM/DD system. Average powers into the fiber of $-5,-1,0,1,2$, and $5 \mathrm{dBm}$ are used in our simulations. 


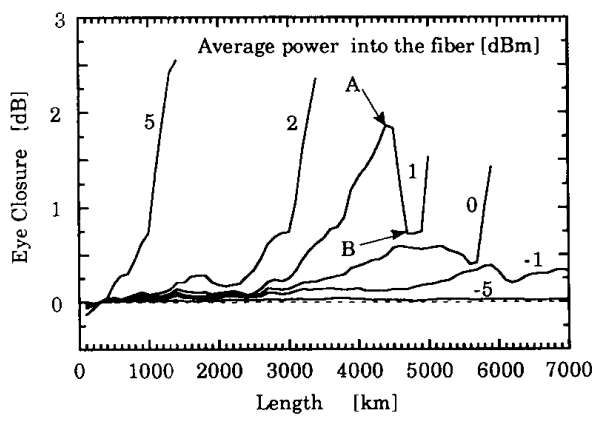

(a)

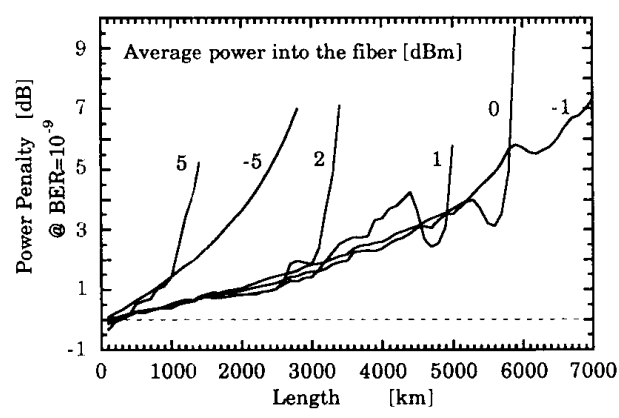

(b)

Fig. 1. (a) Eye closure and (b) power penalty at $B E R=10^{-9}$, as a function of transmission length with the average power of each in-line amplifier into the fiber as a parameter; average powers into the fiber of $-5,-1,0,1,2$, and $5 \mathrm{dBm}$ are used.

When the average power into the fiber is low, e.g., $-5 \mathrm{dBm}$, the eye closure as a function of transmission length is close to zero in Fig. 1(a). This shows that the effect of the firstorder chromatic dispersion is compensated for perfectly by mid-way phase-conjugation because the effect of self-phase modulation (SPM) incurred by nonlinear Kerr effect in the fiber is very small. But the power penalty in Fig. 1(b) is still increased dramatically and smoothly, which is caused mainly by accumulated ASE noise. Consequently, the limitation of the transmission length mainly stems from accumulated ASE noise at low average powers. When the average power into the fiber is high, e.g., $5 \mathrm{dBm}$, the eyes are degraded seriously due to residual first-order chromatic dispersion and residual SPM and the penalty goes up quickly as the transmission length is increased. Since the optical power distributions along the fiber before and after the mid-way phase-conjugator are asymmetrical, only a part of the first-order chromatic dispersion and a part of the SPM are compensated for by midway phase-conjugation. Generally, the compensations for the first-order chromatic dispersion and SPM are reduced when the average power into the fiber is increased. In our simulations the transmission system cannot be operated over more than a $1000-\mathrm{km}$ distance when the average power is lower than -5 or higher than $5 \mathrm{dBm}$.

Fig. 1(b) shows that transmission over $6300 \mathrm{~km}$ results in a power penalty of $5.5 \mathrm{~dB}$ for an average power into the fiber of $-1 \mathrm{dBm}$, transmission over $5700 \mathrm{~km}$ results in a power penalty of $3 \mathrm{~dB}$ for an average power into the fiber of $0 \mathrm{dBm}$,

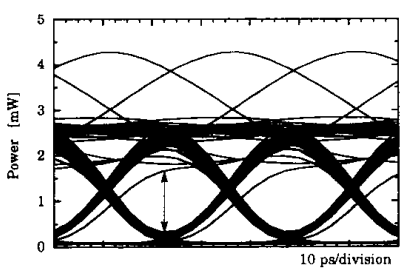

(a)

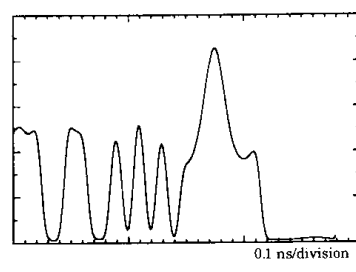

(b)
Fig. 2. Eye-diagram and corresponding partial pulse waveforms at point $\mathrm{A}$ $(4400 \mathrm{~km})$ of Fig. 1(a) for the average power into the fiber of $1 \mathrm{dBm}$.

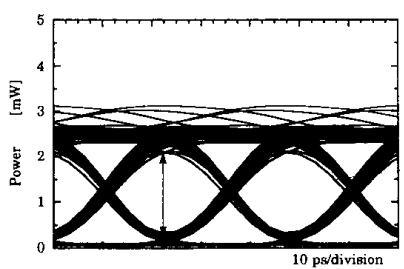

(a)

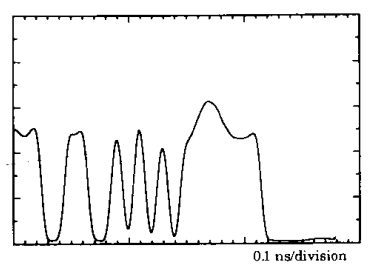

(b)
Fig. 3. As in Fig. 2, but at point B $(4700 \mathrm{~km})$ of Fig. 1(a)

and transmission over $2000 \mathrm{~km}$ results in a power penalty of $1 \mathrm{~dB}$ for the average powers into the fiber of 2,0 , and $-1 \mathrm{dBm}$. Fig. 1(a) and (b) also show that the limitation of the transmission length, for the average powers within this range, stems from both accumulated ASE noise and eye closure. The higher the average power into the fiber is, the stronger the influence of eye closure is due to compensation reductions. The eye closure in Fig. 1(a) and power penalty in Fig. 1(b) are decreased largely at some transmission lengths for each average power; for example, the length $6300 \mathrm{~km}$ for the average power of $-1 \mathrm{dBm}, 5700 \mathrm{~km}$ for $0 \mathrm{dBm}$, and $4700 \mathrm{~km}$ for $1 \mathrm{dBm}$. The detailed understanding can be obtained from the eye diagrams and pulse waveforms. As an example, the eye diagrams and partial pulse waveforms at points $\mathrm{A}$ $(4400 \mathrm{~km})$ and B $(4700 \mathrm{~km})$ of Fig. 1(a) are illustrated in Figs. 2 and 3, respectively. Fig. 2 shows that the eye closure is mainly caused by a pattern-dependent amplitude variation. Furthermore, seven consecutive " 1 " pulses induce stronger SPM, and hence these seven consecutive "1" pulses are compressed. This phenomenon disappears in Fig. 3 (at point B), because of the interplay between the residual first-order chromatic dispersion and the residual SPM. To investigate the effect of the pattern-dependent amplitude variation at point A, we resimulate the system with 15 consecutive " 1 " pulses inserted in the 128-bit sequence. The resulting eye and partial pulse waveforms are illustrated in Fig. 4 . It is seen that 15 consecutive "1" pulses do not give a worse eye-diagram than seven consecutive " 1 " pulses; this fact suggests that the length of PRBS sequence chosen for the simulations has no influence on the prediction of transmission distance.

Even though the second-order chromatic dispersion is included in our simulations, its effect does not influence the results. This can be seen from Fig. 1(a). The eye closure as a function of transmission length is close to zero for the average power of $-5 \mathrm{dBm}$. This indicates that the second-order chro- 


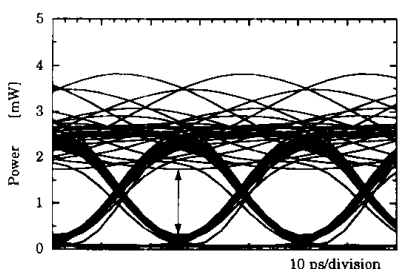

(a)

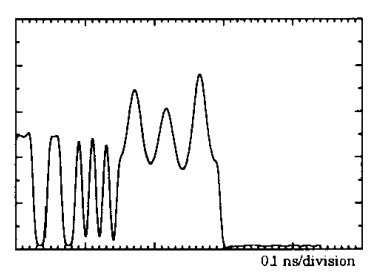

(b)
Fig. 4. As in Fig. 2, but where 15 consecutive "1" pulses are inserted in 128-bit sequence.

matic dispersion does not have any impact on the eye closure even when an ideal mid-way phase-conjugation is inserted and the first-order chromatic dispersion is compensated almost perfectly.

\section{CONCLUSION}

We predict that transmission over more than $6000 \mathrm{~km}$ using standard fiber can be obtained by use of mid-way phaseconjugation in a $1.55-\mu \mathrm{m}, 10-\mathrm{Gb} / \mathrm{s}$ IM/DD system with a power penalty at BER $=10^{-9}$ of less than $6 \mathrm{~dB}$. Under the condition that the power penalty at $\mathrm{BER}=10^{-9}$ is less than $1 \mathrm{~dB}$, a transmission distance of $2000 \mathrm{~km}$ can be achieved if the average power into the fiber is 2,0 , and $-1 \mathrm{dBm}$, respectively. The minimum average power of each in-line amplifier into the fiber must be higher than $-5 \mathrm{dBm}$, where the accumulated ASE noise limits the transmission length, and maximum average power into the fiber must be lower than $5 \mathrm{dBm}$, where uncompensated first-order chromatic dispersion and SPM cause signal distortion and eye closure. All results suggest that standard fiber, with the application of mid-way phase-conjugation, may be a competitive alternative to dispersion-shifted fiber for very-long-distance transmission systems with in-line amplifiers.

\section{REFERENCES}

[1] A. Elrefaie, R. Wagner, D. Atlas, and D. Daut, "Chromatic dispersion limitations in coherent lightwave transmission systems," J. Lightwave Technol., vol. LT-6, pp. 704-709, 1988.

[2] A. Yariv, D. Fekete, and D. Pepper, "Compensation for channel dispersion by nonlinear optical phase conjugation," Opt. Lett., vol. 4, pp. $52-54,1979$

[3] A. Gnauck, R. Jopson, and R. Derosier, "10 Gb/s $360 \mathrm{~km}$ transmission over dispersive fiber using mid-system spectral inversion," IEEE Photon. Technol. Lett., vol. 5, pp. 663-666, 1993.

[4] P. Iannone, A. Gnauck, and P. Prucnal, " $1.5-\mu \mathrm{m} 10-\mathrm{Gb} / \mathrm{s}$ dispersioncompensated transmission over $333 \mathrm{~km}$ of conventional fiber using mid-span spectral inversion in an injection-locked semiconductor laser," in ECOC'94, 1994, pp. 725-728.

[5] M. Tatham, X. Gu, L. Westbrook, G. Sherlock, and D. Spirit, "200 $\mathrm{km}$ transmission of $10 \mathrm{~Gb} / \mathrm{s}$ directly modulated DFB signals using midspan spectral inversion in a semiconductor optical amplifier," $E C O C^{\prime} 94$ 1994, pp. 733-736.

[6] G. Agrawal, Nonlinear Fiber Optics. New York: Academic, 1989.

[7] B. F. Jørgensen, T. Feuchter, C. Jøergensen, and C. Pedersen, "Accurate analysis of optically preamplified direct detection receivers," in ECOC'93, 1993, pp. 425-428. 